\title{
Natal Teeth: A Case Report and Review
}

\author{
Sandeep $\mathrm{S}^{1}$, Namrata $\mathrm{S}^{1}$, Bhumesh $\mathrm{K}^{2}$, Sarita $\mathrm{M}^{2}$ \\ ${ }^{1}$ Consultant Pediatrician, Dept. of Pediatrics, Karnali Academy of Health Sciences, Jumla, Nepal \\ ${ }^{2}$ Dental Surgeon, Dept. of Dental Surgery, Karnali Academy of Health Sciences, Jumla, Nepal \\ Corresponding Author: \\ Dr. Sandeep Shrestha, Consultant Paediatrics \\ E-mail: sandeepshrsth1@gmail.com
}

\begin{abstract}
A rare phenomenon, natal teeth are observed in infants at birth. The incidence of this anomaly has been approximately 1:1000 to 1:6000 live births. Presence of natal tooth may lead to numerous complications. Natal teeth can interfere with breastfeeding and, if excessively mobile, may be swallowed or aspirated during nursing. In this article, a case report is presented where a natal tooth was present in the mandibular incisor region. Due to the possibility of aspiration because of the presence of mobility and also as the teeth are causing discomfort to the mother during breast feeding, the teeth was extracted under topical anaesthesia and the healing was found to be satisfactory.
\end{abstract}

Keywords: Natal teeth, Neonatal teeth, Complication

\section{INTRODUCTION}

Several studies and literature have coined different terms to designate teeth that erupt before the normal time, such as congenital teeth, fetal teeth, predecidual teeth, and dentitia praecox ${ }^{1}$. According to the definition presented by Massler and Savara in 1950, taking only the time of eruption as reference, natal teeth are those observable in the oral cavity at birth and neonatal teeth are those that erupt during the first 30 days of $\operatorname{life}^{2}$. Because of its rare occurrence and appearance, affected children were considered monsters and bearers of misfortune in China in the past ${ }^{3}$.

The incidence of the neonatal and natal teeth has been reported to vary between 1 in 1000 to 6000 live births ${ }^{1-4}$. Studies showed that the incidence of occurrence of natal and neonatal teeth is $85 \%$ in mandibular incisors, $11 \%$ in maxillary incisors, $3 \%$ in mandibular canines and molars and only $1 \%$ in maxillary posterior regions ${ }^{5}$. More than $90 \%$ of natal and neonatal teeth are prematurely erupted whereas less than $10 \%$ are supernumerary ${ }^{6}$. There is no sex predilection in the occurrence of natal teeth ${ }^{7}$. Mostly they are poorly developed with hypo plastic enamel and dentin, poor in texture and have poor or absent development of roots $^{8-9}$.

\section{CASE REPORT}

A 12 days old female neonate was brought to Paediatric out Patient Department (OPD) of Karnali Academy of Health Sciences (KAHS) for evaluation on February 3rd, 2019. Patient's mother's chief complaint was of difficulty in feeding and refusal to suck milk due to presence of teeth in lower anterior region since birth. Family history was non-contributory and insignificant. Oral examination revealed single teeth in the central incisor area of mandibular arch (Figure 1). Teeth exhibited an opaque whitish colouration along with mobility, and inflammation of gingivae around the teeth was also present. 


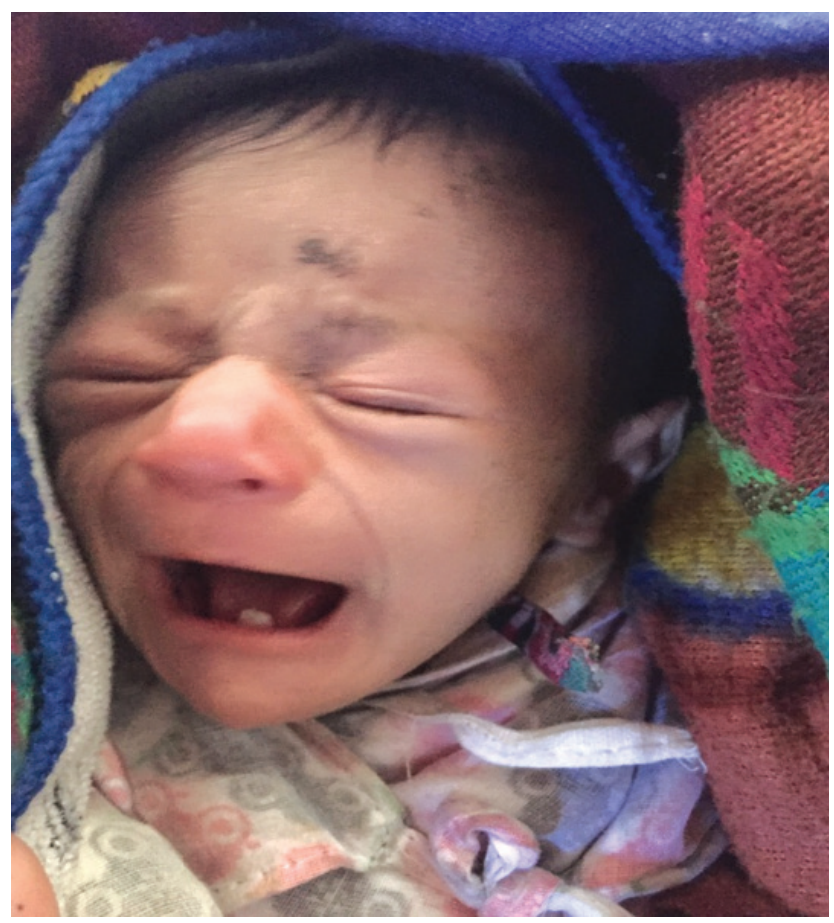

Figure 1: A 12-day-old female infant Showing natal teeth in the mandibular region

Baby was consulted to the dental surgeon of KAHS. He suggested for immediate extraction as the natal tooth was excessively mobile, and so the chances of aspiration. Intramuscularly $1 \mathrm{mg}$ of vitamin $\mathrm{K}$ was administered to prevent haemorrhage and extraction was done under local anaesthesia (LA). The natal teeth were extracted (Figure 2) and the socket was curetted gently to remove any remnants of dental papilla. Immediately after extraction pressure was applied using gauge pack, to reduce bleeding and few minutes later mother was instructed to breastfed the baby as it will cause pressure on the gums and help to stop bleeding. After achieving complete haemostasis, patient was discharged and was recalled after one week, and the recovery was found to be normal.

\section{DISCUSSION}

Natal teeth erupt in the intrauterine period and are present in the infant's mouth during birth. On the other hand, neonatal teeth start erupting following delivery. Studies show that these teeth have no association with normal or deciduous dentition ${ }^{10}$.

In 1997, Helbling classified natal teeth into 4 types based on the clinical appearance ${ }^{11}$

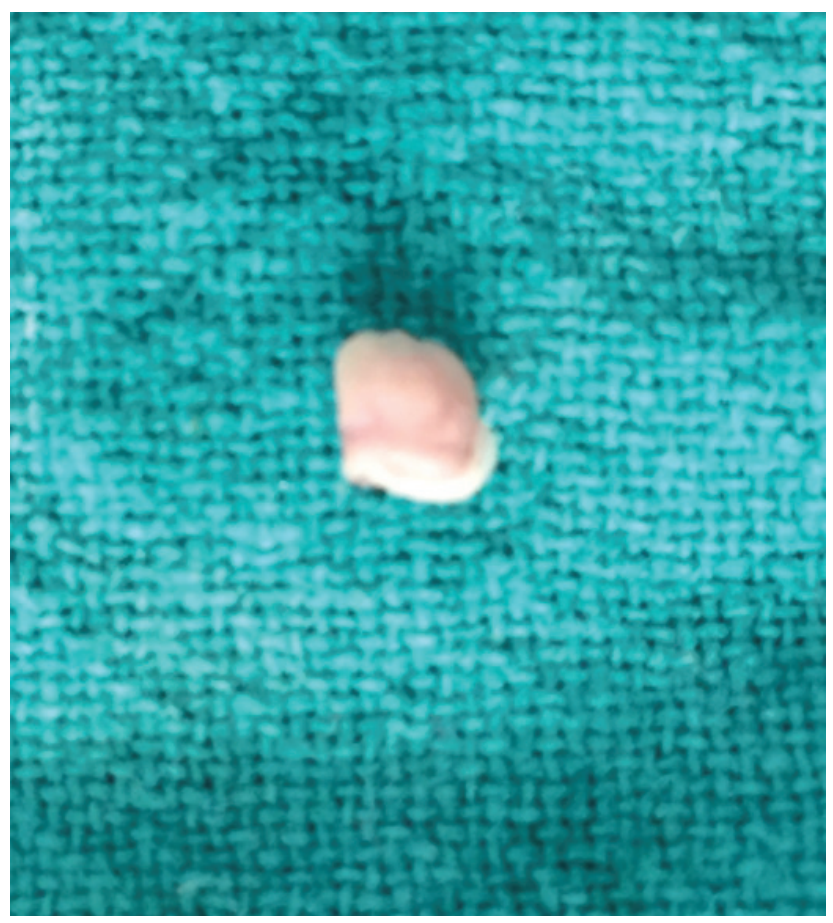

Figure 2: Extracted natal tooth. (Photo taken with consent)

I. Shell-shaped crown, poorly fixed to the alveolus by gingival tissue and absence of a root.

II. Solid crown, poorly fixed to the alveolus by gingival tissue and little or no root.

III. Eruption of the incisal margin of the crown through the gingival tissues.

IV. Edema of gingival tissue with an unerupted but palpable tooth.

Although aetiology is found to be unclear, several factors are considered for the occurrence of natal and neonatal teeth, which are, (i) genetic inheritance (autosomal dominant type) (ii) chemical exposures (iii) syndrome associated (i.e Adrenogenital syndrome, Cleft lip and palate, Craniofacial dysostosis, Craniosynostosis syndromes, Ectodermal dysplasia, Ellis-van Creveld syndrome, Epidermolysis bullosa simplex, Hallerman-Streiff syndrome, JadassohnLewandowsky syndrome) ${ }^{12,13}$ (iv) infection and febrile states (v) malnutrition including hypovitaminosis (vi) trauma leading to abnormal location of the developing tooth germ in relation to the alveolar bone $\mathrm{e}^{14,15}$

Presence of natal teeth can cause risk for neonates which may include (i) risk of swallowing or aspiration if the tooth is excessively mobile (ii) ulceration on the 
ventral surface of tongue due to sharp incisal edges (iii) possibility of traumatic injury and (iv) growth retardation(due to interferance with breastfeeding). Difficulties for the mother due to presence of natal teeth may include (i) inconvenience during suckling and (ii) Injury to the mother's breast such as lacerations ${ }^{16}$

\section{CONCLUSION}

The occurrence of natal teeth is a rare condition in infants. The decision to keep or to extract these teeth should be evaluated in each case, keeping in mind the scientific knowledge, clinical common sense and parental opinion. Parents should be counselled as these condition hold mystic beliefs and treatment modality may vary according to patients risk and complication associated with it. An interdisciplinary approach between the paediatrician, neonatologist, and oral health professional is necessary better oral health.

\section{REFERENCES}

1. Zhu J, King D. Natal e neonatal teeth. J Dent Child 62:123-128, 1995.

2. Massler M, Savara BS. Natal and neonatal teeth: a review of 24 cases reported in the literature. J Pediatr.1950; 36:349-359.

3. Bodenholff J, Gorlin RJ. Natal and neonatal teeth: folklore and fact. Pediatrics 1963;32:1087- 93.

4. Allwright W.C. Natal and neonatal teeth: A study among Chinese in Hong Kong. Br Dent J, 1958; 105: 163-172

5. Bodenhoff J. Natal and neonatal teeth. Odontologisk Tidskrift, 67: 645-695

6. Kates G.A., Needleman H.L., Holmes L.B. Natal and neonatal teeth: a clinical study. J Amer Dent Assoc, 1984; 109: 441-443
7. Leung AK, Robson WL (2006) Natal teeth: A review. J Natl Med Assoc 98: 226-8.

8. Chow MH (1980) Natal and neonatal teeth. J Am Dent Assoc 100: 215-16.

9. Ooshima T, Mihara J, Saito T, Sobue S (1986) Eruption of tooth like structure following the exfoliation of natal tooth: Report of a case. ASDC J Dent Child 53: 275-278.

10. Kimoto S., Suga H., Yamaguchi M., Uchimura N., Ikeda M., Kakizawa T. Hypoplasia of primary and permanent teeth following osteitis and the implications of delayed diagnosis of a neonatal maxillary primary molar. Int J Paediatr Dent, 2003; 13: 35-40.

11. Hebling J, Zuanon ACC, Vianna DR (1997) Dente Natal-A case of natal teeth. Odontol Clín 7(1): 37-40.

12. Alvarez MP, Crespi PV, Shanske AL. Natal molars in Pfeiffer syndrome type 3: A case report. J Clin Pediatr Dent .1993;18:21-4.

13. Babaji P. Oral abnormalities in the Ellisvan Creveld syndrome. Indian J Dent Res. 2010;21(1):143-145

14. Mhaske S, Yuwanati MB, Mhaske A, Ragavendra R, Kamath K, Saawarn S. Natal and neonatal teeth: an overview of the literature. ISRN Pediatr. 2013;2013:956269.

15. Cunha RF, Boer FA, Torriani DD, Frossard WT. Natal and neonatal teeth: review of the literature. Pediatr Dent. 2001;23(2):158-62.

16. Mallineni SK, Nuvvula S (2015) Management of supernumerary teeth in children: A narrative overview on published literature. J Cranio Max Dis. 4: 62-68. 